\title{
AUTONOMÍA INDIVIDUAL Y AUTONOMÍA COLECTIVA COMO FUENTE DEL DERECHO
}

\author{
PATRICIO MASBERNAT ${ }^{1}$
}

RESUMEN: El presente artículo intenta un acercamiento crítico a la categoría dogmática jurídica tradicional de la autonomía privada de carácter individualista como Fuente del Derecho, entendiendo que ella deriva de una ideología que nace y se desarrolla y se entiende en un determinado contexto bistórico. Un nuevo contexto bistórico y social, y nuevos fundamentos del ordenamiento jurídico, demandan nuevos enfoques dogmáticos. Esta apreciación no significa desconocer las aportaciones del liberalismo. En parte de la literatura nacional consultada existe la percepción de que la concepción dogmática de la autonomía privada no responde debidamente a la realidad del fenómeno jurídico, pero sus reflexiones aún muestran un desarrollo insuficiente. Lo mismo sucede con la noción de autonomía colectiva, lo cual limita un mayor desarrollo normativo de ella.

Palabras Claves: Autonomía de la voluntad - Autonomía colectiva Fuentes del Derecho Privado.

ABSTRACT: The present article intends a critical approach to the traditional juridical dogmatic category of the private autonomy of individualistic character as a Source of Law, in the understanding that it derives from an ideology borne, developed, and understood in a given bistoric context. A new historic and social context, and new foundations of the legal ordinance, requires new dogmatic approaches. This perception does not deny the acceptance of the contributions of liberalism. In a portion of the national literature examined, there is the perception that the dogmatic conception of the private autonomy does not adequately respond to the juridical phenomenon reality, but its considerations still evidence an insufficient development. The same occurs with the notion of collective autonomy, which limits a greater regulatory development of it.

Profesor de la Facultad de Ciencias Jurídicas y Sociales de la Universidad de Talca. Magíster en Derecho por la Universidad de Chile, Doctor (c) en Derecho por la Universidad Complutense de Madrid. Correo electrónico: pmasbernatr@utalca.cl Agradezco al Dr. Rodrigo BARCIA LEHMANN al menos un importante comentario general a una versión preliminar, el cual fue considerado, y a los Doctores Irene ROJAS y Fernando ATRIA, por entregarme antecedentes esenciales sobre los cuales construí el presente artículo. Artículo recibido el 16 de diciembre de 2004. Aceptado por el Comité Editorial el 20 de marzo de 2005. 
Key words: Autonomy of will - Collective autonomy - Sources of Private Law.

SUMARIO: I. Acerca de su origen. IL. Acerca de su justificación. III. La autonomía individual. IV. Autonomía colectiva. Configuración y fundamento. Conclusiones finales. Bibliografía.

\section{ACERCA DE SU ORIGEN}

1. El liberalismo clásico ha constituido una ideología fundamental sobre la cual hemos construido nuestro orden jurídico. Uno de sus pilares (la libertad de clave individualista ${ }^{2}$ ) es la base de un importante principio del Derecho Privado, cual es la autonomía de la voluntad. Desde esta perspectiva, ella se entiende como autonomía privada o autonomía individual $^{3}$. A su vez, constituye un elemento importante de las Fuentes de las Obligaciones ${ }^{4}$ y de las Fuentes del Derecho 5 .

La concepción individualista de la autonomía de la voluntad tiene su origen, por una parte, en la reacción frente a un orden jurídico que no respeta la libertad ${ }^{6} ; y$, por otra parte, en las bases jurídico-filosóficas

SÁNCHeZ-ARCILla, J.: Historia del Derecho. Instituciones politicas y administrativas, Dikinson, Madrid, 1995, pp. 965 y ss. Sánchez-Arcilla afirma que la Ilustración engarza con el iusnaturalismo racionalista cuyo énfasis era el individuo y la protección de sus derechos y libertades (op. cit., pp, 786 y ss). Alessandri expresa que su fundamento se encuentra en las doctrinas liberales e individualistas proclamadas por la Revolución Francesa (ALESSANDRI, A.: De los Contratos, Editorial Jurídica de Chile, 1994, p. 10). Diez-Picazo, L. y A. Gillon, Sistema de Derecho Civil, Volumen I, Tecnos, 1988, Madrid, pp. 389 y ss. Aparece entendida exacramente igual como Arturo Alessandri (loc. cit.). Abeliuk las define como los hechos jurídicos que le dan nacimiento o que originan las obligaciones (Abeliuk, R., Las Obligaciones, Tomo I, Editoriales Jurídica Temis S.A.Jurídica de Chile, Colombia, 1993, p. 43).

5 BARRERE, M. A. et al., Lecciones de Teoría del Derecho, Tirant lo Blanch, Valencia, 1998, p. 182. Entendemos la dificultad conceptual de esta noción. Aquí, cuando afirmamos que la autonomía de la voluntad es una fuente del Derecho, significamos que consticuye un fundamento de validez y un factor de producción de normas jurídicas, en sentido general, y constituye un hecho jurídico (en el sentido usado por Abeliuk) del que emanan derechos y obligaciones, en cuanto fuente de las obligaciones. Ver: SQuella, A., Introducción al Derecho, Editorial Jurídica de Chile, 2001, pp. 205 y ss.

- Dicha idea tuvo el merito de situar al hombre en situación de superioridad frente al Estado (SÁNCHEZ-ARCILl. a, op.' cit., p. 965), y de constituir a la libertad como fundamento del orden social y jurídico, rechazando todo fenómeno social que la vulnere, aunque provenga de las organizaciones sociales (de los hombres libremente organizados). Por cierto, en su época no estaba desarrollada una Teoría de los derechos fundamentales incluso con base normativa y constitucional como hoy existe, que precisamente impide la vulneración de la libertad sea por otros miembros de la comunidad, como por organizaciones civiles u órganos estatales. De ahí que consideramos errado trasponer viejos hechos históricos (o viejas ideologías) a los modernos fenómenos sociales. Es decir, que el hecho de que la historia de la humanidad pueda ser vista como la lucha por el reconocimiento de la libertad, no significa necesariamente abominar las actuales formas de asociarividad 
para la construcción de un nuevo orden funcional al proyecto político, económico y social de la burguesía 7 . Por ello, es preciso entender y valorar las doctrinas Iluministas en su contexto histórico, y no estimarlas como dogmas que explican de manera definitiva, permanente y total la complejidad del hombre y de la sociedad, y, por tanto, de las relaciones jurídicas.

Desde su origen hasta nuestros días, diferentes expresiones del liberalismo (diversidad que realmente ha existido desde un inicio hasta hoy ${ }^{8}$ ) han hecho su aporte al Derecho, aun sin considerar la influencia de corrientes de pensamiento distintas a las liberales. Por otro lado, el iusnaturalismo racionalista ${ }^{9}$ de base liberal devino en un Positivismo (influyendo a filósofos del Derecho hasta hoy) que ha visto en el Estado la única (o fundante) Fuente del Derecho ${ }^{10}$. Razones de carácter científico como, asimismo, sucesos históricos de carácter político provocaron una reacción contra el Positivismo que se tradujo contemporáneamente en la idea de fortalecer el derecho fundamental de la libertad, y con ello la autonomía privada como Fuente del Derecho independiente de la voluntad estatal, oponiéndose al intervencionismo estatal y al Estado como monopolizador de la creación del Derecho ${ }^{11}$.

Este esfuerzo plausible desde el contexto de la defensa de los derechos fundamentales, ha significado ciertas confusiones doctrinarias que han perjudicado otros institutos jurídicos igualmente defendibles desde la misma perspectiva, como el principio de comunidad como organizador social (que algunos confunden con el intervencionismos estatal ${ }^{12}$ ). Lo anterior no significa que modernamente muchos autores consideren que el intervencionismo estatal es necesario en ciertos casos excepcionales ${ }^{13}$, tanto como otros han afirmado que los casos en que no opera en la realidad los fundamentos que hacen funcional la autonomía privada al contexto jurídico de respeto de los valores jurídicos liberales (básicamente la libertad, propiedad, igualdad) y que hacen operativa a la libertad contractual, no son tan excepcionales como pudiera parecer, lo cual amplía los ámbitos de intervencionismo estatal ${ }^{14}$. Pero dicho intervencionis-

producidas por las autonomías colectivas debido, precisamente, a que estas últimas también buscan conquistar espacios de libertad, conviviendo con la libertad individual, y no conculcándola. Nuestro análisis busca no alejarse del paradigma liberal acogiendo el dato de la realidad.

7 Topasio, A.: Historia del Derecho, EDEVAL, Valparaíso, 1996, pp. 112 y ss.

8 Como da cuenta SÁnchez-ArCilla (op. cit., 786 y ss), en su origen, y J. Gray "El Liberalismo de Mill y los otros", Estudios Públicos, $N^{\circ} 37,1990$, pp. 91 y ss., modernamente.

SÁNCHEZ-ARCILLA, loc. cit.

BARRERE, M. A. et al., op. cit., p. 43.

DiEz-PICAZO, L. y Gillon, A., loc. cit.

DiEZ-PICAZO, loc. cit.

Diez-Picazo, loc. cit. y Alessandri, loc. cit.

Collin, A., y Capitant, H.: Derecbo Civil, Obligaciones, Vol, 1, Obra Comentada, Editorial Jurídica Universitaria, México, 2002, p. 84. 
mo (tenga mayor o menor justificación) también constituye un desafío para el protagonismo de la sociedad civil y la asociatividad frente a la omnipresencia estatal ${ }^{15}$.

2. Congruentemente con lo finalmente planteado, los hechos comprueban que la construcción de espacios jurídicos en un contexto de libertad no solo se logra a través de una perspectiva individualista (cuya afirmación parece tener mayor fundamento en una ideología que en la realidad $^{16}$ ), pues solo consideran una parte (visión parcial) de la compleja configuración humana. Ella comprende también una faz colectiva o comunitaria del hombre ${ }^{17}$, que debe considerarse por el Derecho (y expresarse en las Fuentes de las Obligaciones y las Fuentes del Derecho), en cuanto ser de naturaleza gregaria y miembro (permanente) de una comunidad $^{18}$. Incluso para algunos liberales clásicos ${ }^{19}$ y modernos ${ }^{20}$, el hombre solo se entiende con relación a su comunidad. Parece ser un hecho hoy sobradamente conocido que, desde la perspectiva antropológica que

15 Diversos sucesos económicos, sociales, históricos (Gran Depresión, guerras mundiales, revoluciones marxistas, la República de Weimar, ascenso de los socialismos y los fascismos, el New Deal, la Doctrina Social de la Iglesia, etc.) fueron provocando la superación o revisión del liberalismo clásico, y con ello, el Estado se va transformando en un organizador social. Ello afectó también los espacios de la autonomía colectiva. Ver: BAYLOS, A.: Derecho del trabajo: un modelo para armar, Madrid, Trotta, 1991, p. 29.

Del mismo modo como se intenta explicar la realidad a través de meros constructos intelectuales como las ficciones jurídicas, que terminan dejando de lado precisamente a la realidad (BARRERE et al., op. cit., p. 64).

Maturana, H.: Transformación en la convivencia, Dolmen, Santiago de Chile, 1999, pp. 91 y ss.

Toda la construcción jurídica individualista adolece de la misma falencia, como se ha dicho. E. Barros expresa con acierto que "la radical individuación que supone la técnica de los derechos encuentra, por cierto, grandes limitaciones y problemas... Las definiciones básicas del derecho tienden a perder su referencia a la comunidad y a fines más generales de la vida común. La publicidad esencial del derecho de la sociedad hace inviable que sea pensado sobre un fundamento radicalmente monológico, desarraigado de la cultura, de formas de vida que nos constituye como personas, incluso en la dimensión de nuestra libertad. Encapsulado en el individuo, dotado de prerrogativas expresadas en derechos subjetivos, el derecho arriesga ignorar su significado relacional". BARros, E.: "Lo Público y lo Privado en el Derecho", Estudios Públicos, $\mathrm{N}^{\circ}$ 81, verano 2001, Centro de Estudios Públicos, Santiago de Chile, 2001. Como J.J. Rousseau. Sobre las existencia de ciertas corrientes liberales que reconocen la importancia de las autonomías colecrivas, ver ATRIA, F., Legalismo, Derecho y Politica, página 10. Se cita la obra ubicada en: http://www.yale.edu/lawweb/lawfac/fiss/ satria.pdfhttp://islandia.law.yale.edu/sela/satria.pdf ( 9 de agosto de 2004, última visita). La edición en papel se encuentra en la obra colectiva "Los Derechos Fundamentales", Alegre, Marcelo et al., Seminario en Latinoamérica de Teoría Constitucional y Política. SELA, 2001. Buenos Aires. 
el hombre se ha desarrollado desde siempre en el seno de comunidades ${ }^{21}$. Dicha característica esconde un principio de cooperación ${ }^{22}$ propio de la conducta y de las relaciones sociales que los hombres desarrollan.

Un acercamiento a dicho aspecto lo podemos efectuar a partir de la categoría jurídica denominada autonomía colectiva, entendida como uno de los dos modos posibles de autonomía privada, diferenciándolo del intervencionismo estatal. Ello está acorde con la actual Teoría de Derechos Fundamentales $^{23}$, con la idea de Estado Democrático de Derecho, con la idea de pluralismo social y jurídico ${ }^{24}$.

\section{ACERCA DE SU JUSTIFICACIÓN}

1. Encontramos otros fundamentos a lo planteado, apoyándonos en las categorías de orden natural, orden heterónomo, orden autónomo, de Friedrich HAYEK ${ }^{25}$.

Es posible distinguir entre orden creado y orden espontáneo ${ }^{26}$. El orden creado o exógeno, también llamado ordenación, puede ser calificado de estructura, orden artificial u organización. El orden autógeno o endógeno, es espontáneo. Estos últimos no obedecen a la voluntad humana, recogen toda la complejidad de la realidad, aun en aquellos aspectos no alcanzados por el conocimiento humano. En efecto, en la perspectiva de HAYEK, la mente humana no es capaz de procesar toda la complejidad de los fenómenos sociales.

Nuestra tesis manifiesta la idea de que el orden jurídico liberal basado en la autonomía individual de la voluntad como única fuente del Derecho derivada de la voluntad, forma parte de una teoría que no comprende a cabalidad el orden espontáneo de las relaciones (sociales y) jurídi-

21 Jacques Flour (citado por López, J: Los Contratos, Volumen I, Editorial Jurídica de Chile, 1986, p. 355), afirma que "el hombre real, el único del cual los historiadores han encontrado trazas, es aquel que vive en sociedad: en todas partes, los derechos del grupo, por pequeño que sea, han precedido los derechos del individuo. La tesis del contrato social es falsa, en tanto cuanto ella afirma la realidad histórica de ese contrato.... Es un lugar común comprobar que la sociedad es natural al hombre, que sin ella nadie podría lograr el respeto de lo esencial de sus intereses materiales y morales".

22 La preferencia humana por la actuación cooperativa es una evidencia racional en las relaciones jurídicas (no solo una actitud natural humana, como lo hemos afirmado), como lo observa Fried. Ver: Fried, C., La Obligación Contractual, Editorial Jurídica de Chile, Santiago, 1996.

23 Cfr., Peces-Barba, G.: Derechos Fundamentales, Latina Universitaria, Madrid, 1980; MEDINA, C. y MERA, J. (editores): Sistema Jurídico y Derechos Fundamentales, Escuela de Derecho de la Universidad Diego Portales, Chile, 1996; Nogueıra, H.: Dogmática Constitucional. Editorial de la Universidad de Talca, 1997, Talca, Chile.

24 BARRERE et al., op. cit., pp. 56 y ss.

25 HAYEK, F.: Derecho, Legislación y Libertad, Tomo I, Madrid, Unión Editorial, 1978, p. 69. 
cas. De ahí que simplifique la realidad social a través de ciertas ideas rectoras (como el individualismo) que son incapaces de captar la complejidad de un orden espontáneo.

Por ello se producen incongruencias dentro del sistema de fuentes del Derecho, que no resiste un análisis basado en la realidad social, lo que genera una reacción (de diverso origen) precisamente contra la teoría (liberal), pues al imponer una estructura u organización esta no reconoce la complejidad del orden espontáneo.

2. Si el liberalismo clásico, en un principio, no reconoció el fenómeno de la asociatividad (salvo en áreas muy reducidas), su orden creado u organización ha impuesto heterónomamente un orden jurídico a las manifestaciones de la voluntad asociativa, sea ignorándolas, prohibiéndolas o proscribiéndolas, o regulándolas (es decir) mediante normas que no provienen de la voluntad de las personas, sino del Estado (o de otra organización institucionalizada). Está claro que (por diversas razones) la desconfianza hacia el fenómeno asociativo espontáneo por parte del Estado aún perdura $^{27}$, y ello se manifiesta precisamente en su enclaustramiento normativo 28 .

3. Las relaciones sociales son reguladas por normas heterónomas, esto es, promulgadas por terceros dotados de fuerza suficiente para imponerla; o por normas autónomas, establecidas por los propios interesados, que regulan su actuación futura.

26 HAYEK (loc, cit.) define orden como un estado de cosas en el cual una multitud de elementos de diversa especie se relacionan entre sí de tal modo que el conocimiento de una parte espacial o temporal del conjunto permite formular, acerca del resto, expectacivas adecuadas o que, por lo menos, gocen de una elevada probabilidad de resultar ciertas. ROJAS, I.: "La Legislación Laboral en Chile en el Ámbito de las Relaciones Colectivas del Trabajo: Control de la autonomía colecriva", en Ius et Praxis, año $6 \mathrm{n}^{\circ} 2,2000$, Universidad de Talca, Chile, 373 y ss.

28 S. Gamonal al referirse a la negociación colectiva atípica (aquella que comprende las negociaciones y los acuerdos de naturaleza colectiva no contemplados en nuestro orde. namiento jurídico, es decir, ajenos al Derecho Estatal), señala que existe un marco legal especialmente restrictivo para la autonomía colectiva. Respecto de su fuerza vinculante, los contratos colectivos atípicos, su naturaleza es extralegislativa e incluso ilegal, implicando que el ordenamiento jurídico no les otorga validez en orden a que las partes puedan exigir obligatoriamente su cumplimiento. Continúa, señalando que en Chile "nos encontramos con una legislación interventora de la autonomía colectiva en el sector privado, que excluye de plano el área pública, y que contempla una normativa penal tan exagerada y anacrónicamente punitiva que, en la práctica, no se aplica". Ver: Gamonal, S.: "La negociación y Contratación Colectiva Atípica", en Revista Laboral Chilena, 1, 1999, Santiago de Chile, pp. 89 y ss. Nuestra posición es menos severa, pues estimamos que en una interpretación sistemática en el contexto del bloque constitucional, las obligaciones nacidas de la autonomía colectiva debieran tener efectos jurídicos. Reconocemos, como veremos, las graves inconsistencia que nuestro ordenamiento jurídico muestra. 
La autonomía, jurídicamente, hace referencia al poder de un sujeto del derecho de atribuirse un ordenamiento, y en tal sentido, es sinónimo de capacidad normativa. La autonomía es individual cuando se refiere a la regulación de los propios intereses o colectiva cuando se refiere a la regulación de los intereses dentro de un grupo o entre varios grupos, sean o no contrapuestos ${ }^{29}$.

Bajo la premisa que plantea que la única fuente del derecho lícita, reconocida o válida derivada de la autonomía de la voluntad tiene naturaleza individual, el único orden autónomo (en el sentido de autonomía normativa) posible es aquel generado a partir de las relaciones jurídicas producidas por ese tipo de Fuente del Derecho entendida en tal perspectiva.

Un orden jurídico construido sobre bases (Fuentes del Derecho) insuficientes, se traduce en el surgimiento de nuevas concepciones que buscan satisfacer dichas insuficiencias jurídicas y reales.

Una insuficiencia real detectada históricamente de este modelo de organización jurídica, se tradujo en que la libertad contractual solo podían ser ejercida por algunos miembros de la sociedad. Ello generó diversas consecuencias en el Derecho Civil, Derecho Comercial y Derecho Laboral $^{30}$, tales como el fenómeno del dirigismo estatal de los contratos. La insuficiencia jurídica, por otra parte, se manifiesta en que dichas bases no responden a la complejidad del fenómeno jurídico ${ }^{31}$.

Otra insuficiencia (jurídica) ha sido la ausencia (relativa), entre las Fuentes del Derecho, de la autonomía colectiva de la voluntad.

Otro ejemplo se relaciona con la estructura de la acción procesal ${ }^{32}$, consecuencia del individualismo jurídico. En la segunda mitad del siglo pasado se desarrolla la concepción de los intereses colectivos, difusos o supraindividuales, que dice relación con categorías de personas unidas por razones laborales, medioambientales, económicas, etc. ${ }^{33}$. Dichos inte-

29 Se le atribuye a Gierke el mérito de ser el primero en identificar el fenómeno de la autonomía, al observar la existencia de un derecho social creado por las corporaciones Ver: O. ERmida et al. Derecho Colectivo del Trabajo, Pontificia Universidad Católica de Perú, Facultad de Derecho, Lima, 1990, p. 34.

30 De ahí la conocida tendencia del Derecho Civil actual hacia el establecimiento de limitaciones a la autonomía privada, a través de normas prohibitivas e imperativas, como consecuencias de la percepción de la existencia de situaciones de desigualdad entre los contratantes, y a fin de evitar abusos. Algunos ligan dicho proceso a diversos fenómenos sociales, políticos y económicos, la difusión de ideas socialistas y el intervencionismo estatal, que se habrían producido en el siglo XX, conforme se ha citado.

31 L. DIEZ-PICAZo explica que "se ha observado también que la figura del contrato no agota ni cubre todas las posibilidades de creación de obligaciones por obra de la voluntad individual o de la autonomía privada". Ver: Diez-PICAZO, L.: Fundamentos de Derecho Civil Patrimonial, Volumen II, Madrid, 1996, p. 138.

32 Colombo, J:: Los Actos Procesales, Editorial Jurídica de Chile, Santiago, 1997, especialmente pp. 167 y ss, y 191 y ss.

33 Existen diferentes concepciones de interés difuso. Señala Stiglitz que lo que caracteriza a los intereses difusos es que existen idénticamente a una pluralidad de sujetos, en cuanto 
reses deben defenderse a través de un tipo de acción procesal construido de manera distinto a la del derecho liberal clásico (el que contempla solo el interés individual como base de la legitimación activa), pues requiere la coordinación de los afectados a veces incluso a través de organizaciones sociales creadas para la concreta defensa de sus intereses colectivos o difusos 34 .

En el Derecho Colectivo del Trabajo, por otra parte, la lucha por el reconocimiento de la autonomía colectiva constituye una reacción frente a ambas insuficiencias (real y jurídica) del Derecho liberal clásico. Bajo la situación social propia de la primera mitad del siglo pasado muchos juristas pensaron que en el marco de la teoría de las Fuentes del Derecho liberal clásico había personas que no podían manifestar su voluntad de manera real (libre), i.e., los trabajadores individualmente considerados ${ }^{35}$, por lo que estos debían valerse de organizaciones sociales y sindicales; y que tal nivel de asociatividad (contrario al orden social liberal de la época) significaba el desarrollo de un antagonismo entre ambos, y por tanto, el alzamiento de las organizaciones de trabajadores contra el orden establecido u organización liberal ${ }^{36}$. Dichos movimiento tuvo expresiones ideológicas no liberales, y con ello, en gran medida las categorías jurídicas dogmáticas de autonomía colectiva fueron construidas sobre otras bases filosóficas (en dicho ámbito), perjudicando su incorporación a un orden jurídico liberal. Sin embargo, la incorporación del instituto de la auto-

integrantes de una categoría, clase o grupo de personas ligadas en vircud de las pretensiones de goce, por parte de cada una de ellas, de una prerrogativa. Ver: STIGlitz, G.: La responsabilidad civil, La Ley, Buenos Aires, 1985, pp. 24 y ss. Una expresión del fenómeno en nuestro país se encuentra en la normativa de la Ley 19.496 sobre Protección de los Derechos de los Consumidores, conforme ha sido modificada por la Ley 19.955 de 14 de julio de 2004.

34 En alguna medida, la idea de interés colectivo está relacionada con la autonomía colectiva, como construcción autónoma de un marco jurídico (o la influencia en este) por parte de un grupo de personas que intentan resolver problemas que les afectan, en sus relaciones internas o con otros grupos. Existen diversos trabajos acerca de la materia. De algún modo concordante a este artículo, ver: PALOMO, D. "Tutela del Medio Ambiente: abandono del paradigma de la litis individual", en Revista de Derecho Universidad Austral de Chile, Vol. XIV, julio 2003, pp. 187-201.

35 Por cierto, a pesar de nuestra afirmación de que todos los derechos tienen una misma matriz o cobertura, y posibilidad de ser defendidos bajo la idea de Derechos Fundamentales, entendemos diversos puntos difíciles de resolver, tales como los diferentes orígenes y estructura de los llamados derechos individuales y sociales. Al respecto, puede estudiarse no solo esos puntos sino otras interesantes perspectivas, que creo no tienen antecedentes, por lo que es interesante además por su novedad, en: ATRIA, F,, “¿Existen Derechos Sociales?", Coloquio "Derecho, Moral y Política", Facultad de Derecho Universidad de Palermo, Argentina, 2002 (nosotros no hemos tenido acceso a la edición impresa citada, pero sí a la electrónica, en: htcp://www.palermo.edu.ar/derecho/eventos/Coloquio01.pdf, última visita el 9 de agosto de 2004).

36 Debe considerarse que también las organizaciones sindicales fueron perseguidas y proscritas. Cfr., Salazar, G: Historia de Chile, Dolmen, 2002. 
nomía colectiva se ha producido en países desarrollados, indudablemente liberales ${ }^{37}$.

\section{LA AUTONOMÍA INDIVIDUAL}

1. Como hemos señalado, el principio de autonomía de la voluntad individual constituye una fuente del Derecho que se encuentra plasmado fuertemente en los Códigos chilenos del siglo XIX, derivados de los mismos de la Europa de la época inmediatamente anterior ${ }^{38}$.

En el marco del Derecho liberal clásico, una versión jurídicamente abstracta del hombre se traduce en el sujeto de Derecho, como centro de imputación de derechos y obligaciones. Esta versión abstracta, ideal y simplificada del hombre concebida por el Derecho liberal clásico, incluye tan solo ciertos elementos o características "de todos los hombres", los que le interesan y le son funcionales, y no todas las características y circunstancias propias de los seres humanos concretos, distinción en la cual el Derecho Privado funda su coherencia. Es decir, para facilitar la contratación entre cualesquiera personas, separa al sujeto de Derecho del sujeto contingente o persona ${ }^{39}$. En tal sentido, no se hace cargo de todo el ser humano ni de todas las relaciones entre las personas, sino de aquellas de carácter patrimonial. Lo anterior se debe a que el Derecho Privado es un mecanismo para solucionar los problemas de cooperación entre los hombres, haciendo necesarias (obligatorias y ejecutables) las relaciones que en principio aparecen contingentes ${ }^{40}$.

Si para el liberalismo la idea de patrimonio y sus alcances constituyen un tema privativo de cada persona (por razones filosóficas, religiosas, morales, económicas, sociales, ideológicas, etc.), es decir, un asunto individual, es natural que como consecuencia de ello el principio fundamental del Derecho Privado sea la autonomía (individual) de la voluntad, subjetivista. La ley, generalmente, servirá para completar la voluntad (función de supletoriedad) o para limitar la autonomía privada en virtud de la idea que el Legislador (es decir, quienes detentan el poder legislativo en un Estado Liberal decimonónico, para efectos de nuestra explica-

37 En el Derecho Comparado existen diferentes formas de reconocer y proteger la autonomía colectiva de la voluntad, tales como mediante el "dejar hacer" (abstencionismo legislativo) como es el caso de Inglaterra, o el reconocimiento de los acuerdos intersindicales como generadores del orden sindical, como es el caso de Italia, Ver: BAYLOS, A.: Derecho del trabajo: un modelo para armar, Madrid, Trotta, 1991, p. 40.

38 ABELIUK, R: op. cit, p. 24.

39 Atria, F.: "Ubi Ius, Ibi Remedium? La Relevancia Jurídica de los Derechos Humanos", en Revista de Estudios de la Justicia, Centro de Estudios de la Justicia, Universidad de Chile, número 3, 2003, pp. 37 y ss. 
ción) tiene del correcto orden social (plasmado en ideales de orden público, moral, buenas costumbres, etc.).

La pretensión de no considerar la faz comunitaria del ser humano (es decir, el hombre con relación a los otros y su comunidad), deja al Derecho Clásico Liberal expuesto a las reformas o adiciones legislativas provenientes de otras matrices ideológicas o paradigmáticas. En efecto, dicho sistema deja flancos expuestos, al no responder al hombre social u hombre cultural (al menos en sus otros aspectos relevantes), entendiendo el Derecho como fenómeno social o cultural.

El reconocimiento o integración de la voluntad colectiva como fuente de las obligaciones, no implica necesariamente romper con la estructura del Derecho liberal (salvo en su versión más clásica), sino que implica integrar un aspecto relevante (innegable) del ser humano como sujeto de Derecho, en este caso, colectivo o comunitario (o como quiera llamársele), en la estructura del ordenamiento jurídico.

Con ello no pretendemos abusar de la ductilidad del derecho, pues entendemos, que el Derecho Privado no sirve para cualquier cosa, no es enteramente flexible, y por tanto, cede ante ciertas circunstancias, ya que tiene una lógica interna que no es infinitamente maleable.

Si bien ATRIA afirma que la importancia de las fuentes de las obligaciones radica en distinguir las relaciones que constituyen Derecho Privado, que consideran un tipo de justicia propia del Derecho Privado, donde lo debido no es "lo debido teniendo todas las cosas consideradas" ${ }^{\prime 1}$, sino que solo determinados aspectos de la relación jurídica, aquellas que le interesan para hacer necesario el cumplimiento, entendemos que la idea planteada de considerar la autonomía colectiva como parte de la autonomía privada continúa siendo posible dentro del mecanismo propio del Derecho Privado.

2. La crítica a la Teoría de las fuentes y de la construcción de la autonomía privada no es nueva. Luis DieZ-PICAZO ${ }^{42}$ da cuenta del fenómeno del "moderno pluralismo de las fuentes de las obligaciones" dado que "el carácter insatisfactorio de la teoría de las fuentes de las obligaciones, que quizás obedezca, más que a cualquiera otra razón, a la imposibilidad o enorme dificultad de sujetar a criterios lógicos de tipo sistemático, fenómenos que son ante todo vitales, ha forzado a la doctrina más reciente a nuevos ensayos y tanteos. En ellas, las anterio-

\footnotetext{
4 Para que el Derecho Privado tenga sentido, debe funcionar bajo las relaciones de Derecho Privado, y por ello, estas son fundamentales, y el legislador no puede crearlas donde quiera, pues la lógica le viene impuesta desde dentro. ATRIA, op. cit., nota 38. Op. cit., p. 139
} 
res tentativas en pro del dualismo y de la simplificación han quedado sustituidas por nuevas formas de pluralismo" 43 .

Pensamos que la crítica a la concepción individualista de los contratos involucra tanto la crítica al individualismo en la autonomía privada, como también importa una crítica a la concepción individualista de las fuentes de las obligaciones (y con ello, de las fuentes del Derecho). Ello se puede advertir en la crítica a la concepción individualista de la contratación que realiza LÓPEZ, cuando afirma que el contrato como producto de la sola voluntad individual es una quimera, pues es un hecho social, y "en una medida que es variable, la voluntad no puede dejar de plegarse a las exigencias del medio social que desarrolla constante influencia sobre los particulares. Solo aquel que razona a partir del hombre aislado puede afirmar la autonomía del individuo" 44 .

Como hemos dicho, el Derecho Liberal en su estructura clásica genera como consecuencia de sus premisas individualistas una Teoría de las Obligaciones del todo insuficiente. La crítica capaz de llevar a una reconstrucción dogmática, sin destruir el aporte del Derecho liberal y a partir de este, para nosotros es posible.

3. Como sabemos, el principio de autonomía de la voluntad ${ }^{45}$, en su enfoque individualista, constituye un principio básico del Código Civil ${ }^{46}$.

43 LÓPEZ (1986) cita a Karl LARENZ, para quien las obligaciones pueden nacer: (1) de los negocios jurídicos, esto es, declaraciones de voluntad negocial unilateral o plurilateral ("el moderno tráfico de masas comporta que en algunos casos, de acuerdo con las concepciones imperantes y con los usos del tráfico, se asuman deberes y nazcan obligaciones sin que se emitan declaraciones de voluntad destinadas a tal fin ("relaciones contractuales de hecho"): (2) de la conducta social típica; (3) de los hechos legalmente reglamentados; (4) de un acto de soberanía estatal con efectos constitutivos en la esfera del Derecho privado. DiezPICAZo, en su recapitulación y ensayo de reconstrucción de las fuentes de las obligaciones (si bien solo hace referencia a la voluntad negocial de los individuos), señala que hay obligaciones que surgen de "relaciones jurídicas de perfiles más amplios, de carácter complejo y de naturaleza diversa". Creemos que abre la puerta a institutos diferentes de la autonomía privada individual, como la autonomía colectiva.

44 LÓPEZ, op. cit., p. 355.

45 W. Flume distingue entre autonomía privada, como la libertad de celebración, de la libertad contractual, definida como la libertad de determinación del contenido de las prestaciones a que se obligan. Sin embargo, para efectos del presente trabajo, no hacemos distinción entre ambos. Flume, W.: El Negocio Jurídico, Tomo II, Fundación Cultural del Notariado, 1998, p. 35.

46 Por ejemplo, Ducci observa que dicho principio se configura en una serie de artículos del citado Código, tales como 12, 1445, 1574, 1631, 1635, 1444, 1545, 767, 1234, 1437, 1560. Ver: Ducci, C.: Derecho Civil. Parte General, Editorial Jurídica de Chile, 1995, pp. 24 y ss. ABELIUK (op, cit. 1993, 24) señala que en virtud del principio de autonomía de la voluntad (individualista) o libre contratación se "otorga a las partes el poder de crear soberanamente toda clase de obligaciones y regularlas como mejor estimen conveniente, sin que el legislador intervenga sino para establecer normas supletorias de su voluntad, libremente derogables por los interesados, y algunas pocas restricciones para limitar los desbordes exagerados de esa voluntad" (construidas sobre los conceptos jurídicos indeterminados orden público y buenas costumbres), establecidas por la ley mediante normas imperativas o prohibitivas. 
En una convención, aunque concurran muchas personas, el Código no deja de lado su perspectiva individualista de la autonomía de la voluntad como fuente de las obligaciones.

ABELIUK explica que en la base de las doctrinas racionalistas se encuentra la idea que la voluntad es la fuente de todo el Derecho, sea directamente (contrato) o indirectamente (ley), pues precisamente el libre despliegue de las facultades individuales es lo más equitativo al constituir el resultado de la composición de los propios intereses ${ }^{47}$. El mismo principio pareciera estar atenuado (en su tenor individualista) al ser reconocidas ciertas instituciones (que aunque restringidas y limitadas en el Código Civil, existen) que derivan de un principio de colaboración de las personas, tales como la sociedad (de cuya regulación destacamos en el artículo 2054) o las corporaciones (destacando el artículo 550) ${ }^{48}$.

Conviene, sin embargo, llamar la atención respecto de que el carácter de las personas jurídicas como ficciones jurídicas construidas a la semejanza de las personas naturales, incorporan un principio individualista en una entidad pluripersonal. En tal sentido, cabe tener presente que hay autores ${ }^{49}$ para los cuales la autonomía colectiva abre paso a categorías de sujetos colectivos autónomos distintos al concepto tradicional de personas jurídicas, dando cuenta de un amplio derecho de asociación.

\section{AUtonomía COLECTIVA. CONFIGURACIÓN Y FUNDAMENTO}

1. Hay diferentes teorías respecto de la naturaleza de los sujetos colectivos (sujetos de autonomía colectiva). Para unos constituyen entes colectivos, y otros ven solo a los individuos agrupados, de modo tal que esta forma de autonomía se especifica en el momento de su ejercicio (titularidad individual pero ejercicio colectivo $)^{50}$. Se ha afirmado que la autonomía colectiva es una fuente distinta de los actos corporativos propios de las personas jurídicas en la configuración del Derecho liberal clásico.

Abeliuk, op. cit., pp. 97 y ss.

48 Kelsen explica la especial característica de las asociaciones, de una manera que lo distingue de los contratos en general. "Un tipo especial de contratos mediante los cuales se producen normas generales son aquellos mediante los cuales se instaura, conforme al Derecho interno de un Estado, un estatuto social, o según el derecho internacional general, la carta de una organización internacional. Se habla entonces de una asociación". El ingreso de un nuevo miembro, implica la aceptación por parte de este de un "orden jurídico parcial válido". Lo anterior, sin referirnos si Kelsen adhirió o no con nuestra idea de pluralismo jurídico, da cuenta de que un jurista positivista puede percibir características especiales en el fenómeno jurídico asociativo. Ver: Kelsen, H.: Teoría Pura del Derecho, Editorial Porrúa, México, 1986, p. 268. 
La autonomía colectiva implica una autonomía de autoorganización (autonomía institucional), una autorregulación interna (autonomía normativa), una autonomía de regulación frente a terceros (a través de convenios, que también significa autonomía normativa), y capacidad de representación del grupo frente a terceros ${ }^{51}$.

2. La autonomía colectiva de la voluntad constituye un tema importante para el Derecho Colectivo del Trabajo, y si bien, como se ha señalado, aparece muchas veces ligada a doctrinas diferentes de la liberal ${ }^{52}$, reconoce su base en la democracia social, la configuración de pluralismo social como principio constitucional. Su expresión juridificada se manifiesta en instrumentos distintos a la ley ${ }^{53}$, pues esta última es expresión de la soberanía estatal.

En el ámbito comparado, es entendida como un derecho a la actividad colectiva que permite a la asociación de que se trate (i.e., sindicato) ejercer todas las acciones legítimas que vayan en busca de su objetivo de defensa de sus intereses, sin restricciones ni trabas de parte de otros particulares o del Estado 54 .

Uno de los debates abiertos trata respecto de si la autonomía colectiva es originaria o derivada de la ley ${ }^{55}$. Ese debate es relevante en ciertos casos en que pareciera ser adecuado establecer legalmente marcos irrenunciables de la relación laboral. A esta altura, estimamos que es clara nuestra opción. Creemos que, aun afirmando su carácter originario, es posible establecer tales limitaciones, al menos en algunas áreas del Derecho (pero ello sin entrar necesariamente a argumentar si es bueno o malo del punto de vista económico o social, por ejemplo, un convenio colectivo in pejus).

En Chile, la autonomía colectiva en materia laboral ${ }^{56}$ aparece reconocida a nivel legal en el Libro III (De las organizaciones sindicales y del delegado del personal) y IV (De la negociación colectiva) del Código del Trabajo, pero fuertemente limitada en su estructura y en su cobertura

51 Dicha esfera intraorganizativa del Derecho requiere la distinción previa entre "sistema interno" (dinámico) y "sistema externo" (debe estar en función del primero, para evitar la ineficacia del Derecho), BAYLOS, op. cit., p. 68 ERMIDA, op. cit., p. 35 .

53 CORREA, M., La negociación colectiva como fuente del derecho del trabajo, Madrid, Universidad Carlos III de Madrid; Boletín Oficial del Estado, 1997, p. 106.

54 Ugarte, J.L.: "Libertad Sindical y Constitución: Como superar una vieja lectura", en Revista Laboral Cbilena, ${ }^{\circ}$ 5, 2000, p. 73.

s5 En una discusión semejante a la de la autonomía individual, como to hemos visto. ERMIDA, O.: "La negociación colectiva peyorativa: algunas consideraciones teóricas", en Revista Laboral Chilena, $\mathrm{n}^{\circ} 2-3,1998$, pp. 70-75.

56 Cfr., TAPIA, F: "Auronomía colecriva y legislación del trabajo", en Revista Laboral Chilena, $\mathrm{n}^{\circ} 8,1992$, pp. 77-82, 
(por ejemplo, ver artículo 306 del Código del Trabajo), de acuerdo hemos visto, en comparación a otros ordenamientos jurídicos ${ }^{57}$.

3. Como hemos señalado, el pluralismo social constituye la base del pluralísimo jurídico, el cual debe tener influencia en las fuentes de las obligaciones y en las Fuentes del Derecho ${ }^{58}$. La Constitución Política de la República de Chile reconoce una concepción de la sociedad y del hombre de carácter comunitario y también liberal (en una síntesis difícil al interpretar y aplicar su normativa ${ }^{59}$ ). También reconoce el pluralismo social, en sus artículos $1^{\circ}, 19$ y 23 , protegiendo las autonomías sociales a través de Ia idea de subsidiariedad, que entronca con el principio de pluralismo social, y que tiene una matriz liberal en MONTESQUIEU y TOCQUeVILle, y otra matriz basada en la Doctrina Social de la Iglesia. La Constitución Política se identifica con esta última ${ }^{60}$.

El artículo $1^{\circ}$ es explícito, al disponer que la sociedad se organiza y estructura a través de los grupos intermedios y les garantiza la adecuada autonomía para cumplir sus propios fines específicos.

El artículo 19, en diversos numerandos reconoce la existencia de los grupos intermedios, siendo muy relevante el numeral 15 que establece el derecho de asociación, más aún si se le conjuga, conforme al artículo $5^{\circ}$ inciso $2^{\circ}$, con los tratados internacionales relativos a derechos humanos suscritos y ratificados por Chile y vigentes. También es relevante desde una perspectiva de interpretación sistemática el numeral 16 relativo al derecho de negociación colectiva y el numeral 19 relativo a la libertad sindical. Sin embargo, las limitaciones (o condicionamientos de los derechos) que esos numerales incorporan no son entendibles desde la perspectiva del pluralismo social en el marco de un Estado Democrático de Derecho $^{61}$ (y el respeto a los Tratados sobre Derechos Humanos suscritos y ratificados por nuestro país).

El numeral 21 que reconoce el derecho a desarrollar cualquiera actividad económica, bajo el parámetro de la asociatividad, también presenta problemas de aplicación con la existencia de condicionamientos que

57 Rojas, I.: "Los Instrumentos Colectivos y la Necesaria Organización Laboral", en Ius et Praxis, año $5 \mathrm{n}^{\circ} 2,1999$, Universidad de Talca, Chile, 31 y ss.

58 ERmida (Derecho Colectivo del Trabajo, p. 38.) afirma que la autonomía colectiva, en una organización política que traduzca una sociedad libre, pluralista y democrática, debe ser incluida o considerada un instituto de Derecho Privado. ZÚNígA, F.: "Tendencia contemporáneas de interpretación constitucional", en Interpretación, Integración y Razonamiento Jurídicos, Editorial Jurídica de Chile, Santiago, 1992.

60 Cfr:: Verdugo, M. et al:: Derecho Constitucional, Tomo I, Editorial Jurídica de Chile, 1999. J. L. Cea señala que la doctrina de la Constitución es la subsidiariedad como principio de organización social no estatal. Ver: CEA, J.L., El sistema Constitucional de Chile, Facultad de Ciencias Jurídicas y Sociales, Universidad Austral de Chile, 1999, pp. 149 y ss.

61 En un sentido que compartimos en general, ver la obra citada de J.L. UGARTE. 
normalmente solo fundamentan toda clase de limitaciones a la asociatividad y al despliegue de los derechos y libertades fundamentales ${ }^{62}$.

4. Conforme a lo indicado, debemos además considerar los tratados internacionales relativos a derechos humanos suscritos y ratificados por Chile y que se encuentren vigentes, que forman parte de la Constitución (bloque de constitucionalidad).

Los Tratados citados se refieren al derecho de asociación en sus diversos aspectos, y pueden relacionarse al principio de autonomía colectiva a través de una interpretación sistemática ${ }^{63}$ (debido a que es la forma de integrar dicha categoría jurídica a nuestro sistema), como una expresión de derechos fundamentales, conforme a los cuales debe interpretarse la Constitución y ordenarse el sistema jurídico ${ }^{64}$. Revisaremos brevemente algunos de esos tratados.

La Declaración Universal de Derechos Humanos en su artículos 20 establece el derecho de asociación y en su artículo 23 el derecho de sindicación. Su ejercicio puede ser limitado por ley con el único fin de asegurar el reconocimiento y el respeto de los derechos y libertades de los demás, y de satisfacer las justas exigencias de la moral, del orden público y del bienestar general en una sociedad democrática.

La Convención Americana Sobre Derechos Humanos reconoce la libertad de asociación en su artículo 16, para todo tipo de fines, incluyendo económicos, laborales, sociales. Ello es relevante, porque refiere una posibilidad muy amplia de autonomía colectiva, sobre todo en lo relativo a negociaciones con toda clase de interlocutores, a todo nivel, en relación a sus fines específicos (dichos contenidos de negociación se señalan en los Tratados de Derechos Humanos y en los Convenios de la OIT ${ }^{65}$ ). En su numeral 2 establece que "el ejercicio de tal derecho solo puede estar sujeto a las restricciones previstas por la ley que sean necesarias en una

62 Ver: Fermandois, A., Derecho Constitucional Económico, Tomo I, 2001, Ediciones Universidad Católica de Chile, passim, en lo relativo a las limitaciones de toda clase ha sido expuesta esta libertad. Más específicamente, ver P. Masbernat y J.T. Hurtado, "Crítica al concepto de orden público", de pronta publicación, en Revista de Derecho Público, de la Universidad de Chile.

63 Que es la que cabe en materia de derechos fundamentales. Cfr. Nogueira, op. cit., pp. 140 y ss.

64 Ibidem.

65 Por ejemplo, el Convenio 154 de la OIT sobre la negociación colectiva, 1981, señala en su artículo 2 que "a los efectos del presente Convenio, la expresión negociación colectiva comprende todas las negociaciones que tienen lugar entre un empleador, un grupo de empleadores o una organización o varias organizaciones de empleadores, por una parte, y una organización o varias organizaciones de trabajadores, por otra, con el fin de: a) fijar las condiciones de trabajo y empleo, o b) regular las relaciones entre empleadores y trabajadores, o c) regular las relaciones entre empleadores o sus organizaciones y una organización o varias organizaciones de trabajadores, o lograr todos estos fines a la vez". 
sociedad democrática o los derechos y libertades de los demás". Esto es relevante porque implica limitaciones a la soberanía del Estado en relación a las autonomías sociales.

El Protocolo Adicional a la Convención Americana Sobre Derechos Humanos en Materia de Derechos Económicos, Sociales y Culturales en su artículo 8 establece los Derechos Sindicales, reconociendo la autonomía colectiva en literal $a$, el derecho a las organizaciones de trabajadores de todos los niveles y su libre funcionamiento. La posibilidad de restricción y limitación de este derecho es semejante al caso anterior, y básicamente hacen referencia a los propios a una sociedad democrática y la salvaguardia de los derechos y las libertades de los demás. El artículo 5 es interesante, porque agrega otras exigencias, indicando que "los Estados partes solo podrán establecer restricciones y limitaciones al goce y ejercicio de los derechos establecidos en el presente Protocolo mediante leyes promulgadas con el objeto de preservar el bienestar general dentro de una sociedad democrática, en la medida que no contradigan el propósito y razón de los mismos".

El Pacto Internacional de Derechos Civiles y Politicos de las Naciones Unidas reconoce en su artículo 22, numeral 1, que "toda persona tiene derecho a asociarse libremente con otras, incluso el derecho a fundar sindicatos y afiliarse a ellos para la protección de sus intereses". A continuación, en su numeral 2, establece una norma de limitación estatal del derecho semejante a Convención Americana Sobre Derechos Humanos.

El Pacto Internacional de Derechos Económicos, Sociales y Culturales de las Naciones Unidas reconoce en su artículo 8 la libertad sindical, describiéndolo en su numeral 1 , y dándole un alcance más allá de lo meramente laboral, esto es, al entorno de las relaciones del trabajo, tales como la protección de sus intereses económicos y sociales. Ello abre la puerta a las negociaciones de Pactos Sociales, Económicos y Laborales a nivel nacional, regional, sectorial, etc., que debieran tener efectos jurídicos sin restricciones, salvas los que establece el mismo, que es congruente con el resto de los pactos (por ello discrepamos de S. GamONAL). Este Pacto es un instrumento jurídico autoejecutable. El artículo 4 establece que "los Estados Partes en el presente Pacto reconocen que, en ejercicio de los derechos garantizados conforme al presente Pacto por el Estado, este podrá someter tales derechos únicamente a limitaciones determinadas por ley, solo en la medida compatible con la naturaleza de esos derechos y con el exclusivo objeto de promover el bienestar general en una sociedad democrática".

De manera más específica, pero aludiendo como hemos dicho a una interpretación sistemática del Derecho Constitucional chileno sobre la base del bloque de constitucionalidad, haremos referencia precisa a los Convenios de la Organización Internacional del Trabajo (OIT). 
Los convenios número 87 Sobre la Libertad Sindical y la Protección del Derecho de Sindicación (basado en la libertad de expresión y de asociación) y número 98 Sobre el Derecho de Sindicación y de Negociación Colectiva, no hacen sino pormenorizar las obligaciones que los Tratados imponen al Estado de Chile, y que ya prefigurara la Declaración de la OIT Relativa a los Principios y Derechos Fundamentales en el Trabajo y su Seguimiento. Dichos convenios establecen obligaciones negativas (de abstención), indicando que "las autoridades públicas deberán abstenerse de toda intervención que tienda a limitar este derecho o a entorpecer su ejercicio legal" y obligaciones positivas (de promoción), en cuanto deberán los Estados suscriptores "adoptar medidas adecuadas a las condiciones nacionales, cuando ello sea necesario, para estimular y fomentar entre los empleadores y las organizaciones de empleadores, por una parte, y las organizaciones de trabajadores, por otra, el pleno desarrollo y uso de procedimientos de negociación voluntaria, con objeto de reglamentar, por medio de contratos colectivos, las condiciones de empleo" 66 . Los procedimientos son múltiples, como explica la Recomendación 91 de la OIT Sobre los Contratos Colectivos.

Tener presente estas disposiciones son de extrema importancia, considerando que la legislación interna debe interpretarse conforme a la Constitución Política, y esta debe interpretarse conforme a los derechos fundamentales ${ }^{67}$.

5. Si estimamos que en Chile se encuentra reconocido el pluralismo social en el ámbito constitucional, estimamos que es difícil justificar discriminaciones en perjuicio de la autonomía colectiva, sobre la base de doctrinas liberales individualistas decimonónicas (o cualquier otra). Es decir, la existencia de grupos sociales y el reconocimiento de su poder de autodeterminación y regulación (en los términos señalados) implica superar la vieja dicotomía Estado-Individuo (y las categorías rígidas derivadas de coerción-autonomía privada individual).

\section{CONSIDERACIONES FINALES}

1. Luego de lo señalado, puede surgir la pregunta acerca de las diferencias entre las obligaciones derivadas de la autonomía colectiva de aquellas derivadas de la autonomía individual. No es precisamente el tema del presente estudio, salvo en los aspectos ya presentados. Pero podemos sintetizar algunos elementos ya esbozados.

\footnotetext{
66 Estos Convenios están suscritos y ratificados. Ver Corvera, D. y Gumucio, J.: "Las Normas de los Convenios 87 y 98 de la OIT", en Revista Laboral Chilena, n7, 2000, pp. 65-74. Nogueira, op. cit., pp. 140 y ss.
} 
La distinción puede estar en la mayor permanencia de aquellas obligaciones derivadas de la autonomía colectiva, su mayor alcance, la mayor importancia del comportamiento de los involucrados y de las conductas sociales y situaciones de hecho, y los efectos vinculantes incluso respecto de algunos quienes no han tomado la decisión de obligarse o la decisión específica de que se trata.

De lo anterior, es que se puede deducir que su interpretación debiera ser más objetiva, lo mismo que el juzgamiento del alcance de la buena fe y de la responsabilidad civil. Es posible apreciar obligaciones que nacen ya en las relaciones precontractuales.

Las relaciones jurídicas nacidas de imperativos de cooperación pueden ser necesarias y no siempre voluntarias. Es decir, muchas veces la colaboración ${ }^{68}$ o participación no se debe al hecho de querer obligarse, sino del deber de cooperar, generalmente por existir una situación o por encontrarse en una situación en la cual el deber es precisamente el de cooperar. De ahí que se pueda producir una vinculación de lealtad objetiva muy fuerte entre los sujetos vinculados, pertenezcan a un mismo grupo o pertenezcan a grupos de intereses diferentes que se encuentren unidos por razones diversas (consumidores, asociados mercantiles o en cooperativas, trabajadores, en negociaciones comerciales o laborales, entre miembros de asociaciones diversas, etc.).

La perspectiva comunitaria o colectiva en el Derecho, nos lleva a buscar, además, una idea de responsabilidad colectiva diferente a la establecida en nuestro Código Civil. Asimismo, debieran considerarse la influencia en la estructura de otros institutos, objetivizando la responsabilidad civil y generando otra estructura de la acción proce$\mathrm{sal}^{69}$.

2. Podemos concluir que el actual Derecho en Chile está construido sobre la base de los Derechos Fundamentales y la dogmática constitucional. El Derecho, por tanto, a nuestro juicio, debe ser entendido conforme al bloque constitucional ${ }^{70}$, y además conforme a viejas doctrinas (sea cual fuere, y por muy grande haya sido su contribución al Derecho) solo en la medida que no se planteen como contradictorias al primero.

Ello se traduce en abandonar las posiciones legalistas, considerar que la Constitución Política (como bloque constitucional) está constituida por normas autoejecutables y de aplicación directa que se su-

68 FlumE (op. cit., p. 30.) se refiera a la configuración autónoma de las relaciones jurídicas que necesita de la colaboración de varios sujetos.

69) Stiglitz, G.: La responsabilidad civil, La Ley, B. Aires, 1985, p. 54.

70 En el sentido que lo entiende Nogueira, op. cit., passim. 
perponen a las leyes y reglamentos y demás normas, y que los Tribunales deben reconocerlos en todas sus instancias ${ }^{71}$.

3. También implica que el Derecho debe reconocer (sin abandonar la técnica propia del Derecho Privado) la faz individual y social del hombre (no disyuntivas sino complementarias), como partes indisolubles de este, el que se desarrolla en un contexto social, y que por tanto en este tiene la posibilidad de generar normas que le son vinculantes, sea a través de su autonomía privada o de la autonomía colectiva. Dichas normas colectivas debieran considerarse constructoras de relaciones jurídicas con estabilidad y permanencia, más allá de los sujetos que temporalmente pertenezcan a un grupo, pero siempre sometidos al bloque constitucional y bajo el sistema de competencias que establece la Constitución, es decir, dentro de los parámetros del Estado de Derecho y una sociedad democrática y pluralista (con sus componentes de control y responsabilidad). La determinación del Derecho a los casos concretos ${ }^{72}$ precisamente, debiera ser objeto de la llamada jurisdicción constitucional de la libertad ${ }^{73}$.

\section{BIBLIOGRAFÍA}

- Abeliuk, R.: Las Obligaciones, Tomo I, Editoriales Jurídica Temis S.A.- Jurídica de Chile, Colombia, 1993.

- Alessandri, A.: De los Contratos, Editorial Jurídica de Chile, 1994.

- Atria, F.: "Legalismo, Derecho y Política", página 10. Se cita la obra ubicada en: http://www.yale.edu/lawweb/lawfac/fiss/ satria.pdfbttp://islandia.law.yale.edu/sela/satria.pdf ( 9 de agosto de 2004, última visita). La edición en papel se encuentra en la obra colectiva "Los Derechos Fundamentales", Alegre, Marcelo y otros, Seminario en Latinoamérica de Teoría Constitucional y Política. SELA, Buenos Aires, 2001.

- Atria, F.: “Existen Derechos Sociales?”, Coloquio "Derecho, Moral y Política", Facultad de Derecho Universidad de Palermo, Ar-

71 Fernández, M. A., "La fuerza normativa de la Constitución", en Revista de Derecbo Público, Vol. 63. Facultad de Derecho. Universidad de Chile, Santiago, 2001, pp. 77 y ss.

72 En el sentido que se ha entendido en el derecho contemporáneo. Ver al respecto, LiFANTE, 1.: La interpretación juridica en la teoria del derecho contemporánea, Madrid, Centro de Estudios Políticos y Constitucionales, 1999, passim.

73 ZúNíga, F.: Elementos de Jurisdicción Constitucional, Tomo I, 2002, Universidad Central de Chile, pp, 107 y ss. 
gentina, 2002 (nosotros no hemos tenido acceso a la edición impresa citada, por lo que accedí a la contenida en: http:// www.palermo.edu.ar/derecho/eventos/Coloquio01.pdf, última visita el 9 de agosto de 2004).

- Atria, F., "Ubi Ius, Ibi Remedium? La Relevancia Jurídica de los Derechos Humanos", en Revista de Estudios de la Justicia, Centro de Estudios de la Justicia, Universidad de Chile, número 3, 2003.

- Barrere, M. A. et al.: Lecciones de Teoría del Derecho, Tirant lo Blanch, Valencia, 1998.

- Barros, E.: "Lo Público y lo Privado en el Derecho", en Estudios Públicos, No 81, verano 2001, Centro de Estudios Públicos, Santiago, 2001.

- Baylos, A.: Derecho del trabajo: un modelo para armar, Madrid, Trotta, 1991.

- CeA, J.L.: El sistema Constitucional de Chile, Facultad de Ciencias Jurídicas y Sociales, Universidad Austral de Chile, 1999.

- Collin, A., y Capitant, H.: Derecho Civil, Obligaciones, Vol. 1, Obra Comentada, Editorial Jurídica Universitaria, México, 2002.

- Colombo, J.: Los Actos Procesales, Editorial Jurídica de Chile, Santiago, 1997

- Correa, M.: La negociación colectiva como fuente del derecho del trabajo, Madrid, Universidad Carlos III de Madrid; Boletín Oficial del Estado, 1997.

- Corvera, D. y Gumucio, J.: Las Normas de los Convenios 87 y 98 de la OIT, en Revista Laboral Chilena, $\mathrm{n}^{\circ}$ 7, 2000.

- Diez-PiCazo, L. y Gillon, A.: Sistema de Derecho Civil, Volumen I, Tecnos, Madrid, 1988.

- Diez-PiCAzo, L.: Fundamentos de Derecho Civil Patrimonial, Volumen II, Madrid, 1996.

- Ducci, C.: Derecho Civil Parte General, Editorial Jurídica de Chile, 1995.

- Dworkin, R.: "El liberalismo", en Public and Private Morality, Cambridge University Press, 1978

- ERmida, O. et al:: Derecho Colectivo del Trabajo, Pontificia Universidad Católica de Perú, Facultad de Derecho, Lima, 1990.

- ERMIDA, O.: "La negociación colectiva peyorativa: algunas consideraciones teóricas", en Revista Laboral Cbilena, n 2-3, 1998

- Fermandois, A.: Derecbo Constitucional Económico, Tomo I, Ediciones Universidad Católica de Chile, 2001.

- FERnÁndez, M. A.: "La fuerza normativa de la Constitución", en Revista de Derecho Público, Vol. 63. Facultad de Derecho. Universidad de Chile, Santiago, 2001.

- Flume, W.: El Negocio Jurídico, Tomo II, Fundación Cultural del Notariado, 1998. 
- Fried, C.: La Obligación Contractual, Editorial Jurídica de Chile, Santiago, 1996.

- Gamonal, S.: "La negociación y Contratación Colectiva Atípica", en Revista Laboral Chilena, 1, año 1999, Santiago de Chile.

- Gray, J.: El Liberalismo de Mill y los otros, Estudios Públicos, No 37, 1990.

- Hayek, F.: Derecho, Legislación y Libertad, Tomo I, Madrid, Unión Editorial, 1978.

- Kelsen, H.: Teoría Pura del Derecho, Edit. Porrúa, México, 1986.

- Lifante, I.: La interpretación jurídica en la teoría del derecho contemporáneo, Madrid, Centro de Estudios Políticos y Constitucionales, 1999.

- López S. M., J.: Los Contratos, Volumen I, Editorial Jurídica de Chile, 1986.

- Masbernat, P. y Hurtado, J.T.: "Crítica al concepto de orden público", de pronta publicación, en Revista de Derecho Público de la Universidad de Chile.

- Maturana, H.: Transformación en la convivencia, Dolmen, Santiago de Chile, 1999.

- Medina, C. y Mera, J. (editores): Sistema Jurídico y Derechos Fundamentales, Escuela de Derecho de la Universidad Diego Portales, Chile, 1996.

- Nogueira, H.: Dogmática Constitucional. Editorial de la Universidad de Talca, Talca, 1997.

- Palomo, D.: "Tutela del Medio Ambiente: abandono del paradigma de la litis individual", en Revista de Derecho Universidad Austral de Chile, Vol. XIV, julio 2003.

- Peces-BArba, G.: Derechos Fundamentales, Latina Universitaria, Madrid, 1980.

- RojAs, I.: "Los instrumentos colectivos y la necesaria organización laboral", en Ius et Praxis, año 5 n$^{\circ}$ 2, 1999, Universidad de Talca, Chile.

- Rojas, I.: "La Legislación Laboral en Chile en el Ámbito de las Relaciones Colectivas del Trabajo: Control de la autonomía colectiva”, en Ius et Praxis, año $6 \mathrm{n}^{\circ}$ 2, 2000, Universidad de Talca.

- SÁnCHeZ-ArCilla, J.: Historia del Derecho. Instituciones políticas y administrativas, Dikinson, Madrid, 1995.

- SQuella, A.: Introducción al Derecho, Editorial Jurídica de Chile, 2001.

- Stiglitz, G.: La responsabilidad civil, La Ley, Buenos Aires, 1985.

- TAPIA, F.: "Autonomía colectiva y legislación del trabajo", en Revista Laboral Chilena, $\mathrm{n}^{\circ} 8,1992$.

- Topassio, A.: Historia del Derecho, EDEVAL, Valparaíso, 1996. 
- Ugarte, J. L.: "Libertad Sindical y Constitución: cómo superar una vieja lectura", en Revista Laboral Chilena, n 5, 2000.

- Verdugo, M. et al.: Derecho Constitucional, Tomo I, Editorial Jurídica de Chile, 1999.

- ZÚÑIGA, F.: "Tendencia contemporánea de interpretación constitucional", en Interpretación, Integración y Razonamiento Jurídicos, Editorial Jurídica de Chile, Santiago, 1992.

- ZÚNigA, F.: Elementos de Jurisdicción Constitucional, Tomo I, Universidad Central de Chile, 2002. 